\title{
Paracoccidioidomicose crônica multifocal tendo como primeira manifestação o envolvimento palpebral: relato de caso
}

\author{
Chronical and multifocal paracoccidioidomycosis having \\ the lid involvement as the first sign: case report
}

\author{
Tiago Nelson de Oliveira Rassi ${ }^{1}$ \\ Rafael Ricardo Barcelos Passos ${ }^{2}$ \\ Karina Mitiko Kumagai ${ }^{3}$ \\ João Edward Soranz Filho ${ }^{4}$ \\ João Alber to Holanda de Freitas ${ }^{5}$
}

\section{RESUMO}

O acometimento ocular da paracoccidioidomicose é raro e quando ocorre é geralmente secundário à disseminação hematogênica. Descrição de um caso de paracococcidioidomicose multifocal em homem de 73 anos com história de trauma contuso no olho direito por pedaço de madeira e que teve como primeira manifestação clínica lesão palpebro-conjuntival. Interrogase possível infecção primária ocular por contiguidade e alerta-se para a manifestação da doença em idade mais avançada.

Descritores: Paracoccidioidomicose/diagnóstico; Doenças palpebrais; Diagnóstico diferencial; Pálpebras/patologia; Conjuntiva; Relatos de casos

\section{INTRODUÇ̃̃̃O}

A paracoccidioidomicose (Pbmicose) também chamada de blastomicose sul-americana, foi descrita pela primeira vez por Adolfo Lutz no começo do século passado, sendo o Brasil considerado área endêmica, acometendo tipicamente trabalhadores rurais do sexo masculino com faixa etária entre 30 e $60 \operatorname{anos}^{(1)}$.

A doença apresenta extenso espectro de manifestações clínicas que vai desde a doença localizada benigna até o quadro sistêmico multifocal, de difícil tratamento e de alta letalidade. A Pbmicose crônica multifocal do adulto é a forma de apresentação clínica mais frequente, tendo predileção para os pulmões, mas podendo acometer, simultaneamente, vários outros órgãos ${ }^{(2)}$.

O acometimento ocular é raro e quando presente é geralmente secundário, podendo produzir lesões palpebrais, conjuntivite, úlceras corneanas e uveíte ${ }^{(3)}$.

É descrito a seguir um caso de Pbmicose multifocal que apresentou como primeira manifestação clínica lesão tumoral palpebral em homem de 73 anos após trauma contuso no olho direito com pedaço de madeira.

\section{RELATO DO CASO}

H.P.S, 73 anos, masculino, lavrador, natural de Itapeva (SP), procedente de Ribeirão Branco (SP). Foi admitido no ambulatório de oftalmologia do Conjunto Hospitalar de Sorocaba, em 30/08/2007 com história de inchaço na região periocular direita, hiperemia e visão embaçada há seis meses. Relatava trauma contuso com pedaço de madeira um ano antes (em setembro de 2006). Referia dor e discreta hiperemia na ocasião. Na época não 
procurou assistência médica. Não apresentava queixas como astenia ou dificuldade respiratória. Negava tabagismo e alcoolismo. Hipertenso há um ano em uso de captopril $25 \mathrm{mg} /$ dia com bom controle.

Ao exame físico notava-se pálpebra inferior e superior infiltradas com tumoração ulcerada em borda palpebral superior, edema perilesional acompanhado de secreção mucoide, hiperemia conjuntival e quemose (Figura 1). Acuidade visual com a melhor correção era de 0,15 no olho direito e 0,3 no olho esquerdo. À biomicroscopia a córnea se apresentava clara com catarata nuclear $1+\mathrm{em}$ ambos os olhos. No exame fundoscópico notou-se drusas perimaculares na região nasal e temporal de olho esquerdo.

Realizada biopsia da lesão tumoral que mostrou intenso infiltrado inflamatório linfocitário com histiócitos e numerosas células gigantes multinucleadas, distribuídas em arranjos granulomatosos. A coloração de Grocott evidenciou estruturas fúngicas consistentes com Paracoccidioides brasiliensis (Figura 2). $\mathrm{O}$ exame radiológico de tórax evidenciou infiltrado intersticial bilateral, os sorológicos e de sangue se mostraram inalterados.

O paciente foi encaminhado ao setor de Moléstias Infecciosas do Conjunto Hospitalar de Sorocaba onde foi iniciado tratamento sistêmico com sulfametoxazol $160 \mathrm{mg}+$ trimetropim $800 \mathrm{mg}$ de $12 \mathrm{em} 12$ horas. O tratamento oftalmológico foi realizado com colírio antibiótico Nepodex ${ }^{\circledR}$. Um mês após o início do tratamento se apresentava com lesão fibrosa, granulomatosa na pálpebra superior e inferior associado a simbléfaro temporal e discreto ectrópio na região palpebral inferior.

\section{COMENTÁRIOS}

Micose endêmica de grande interesse para os países da América Latina, o Pbmicose é causado pelo fungo termo dimórfico Paracoccidioides brasiliensis. Na natureza apresenta-se como estruturas filamentosas contendo propágulos infectantes chamados conídios. Uma vez inalados, os propágulos dão origem a formas leveduriformes do fungo que constituirão sua forma parasitária nos tecidos do hospedeiro. Até recentemente, os humanos eram tidos como os únicos hospedeiros naturalmente infectados por este fungo. Atualmente,

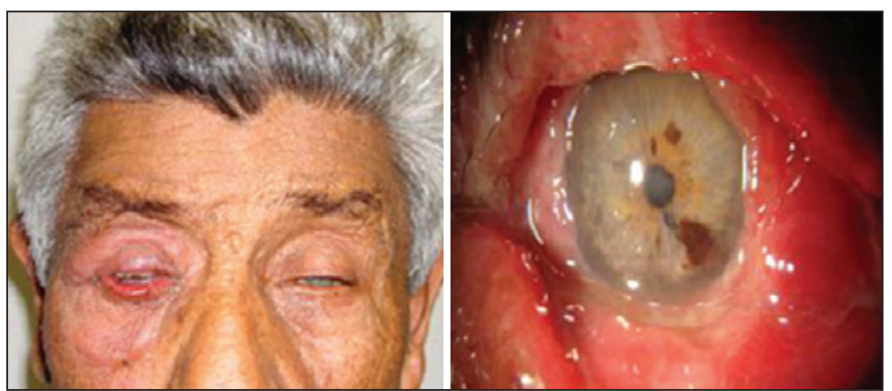

Figura 1 - Lesão pré-tratamento alguns animais foram encontrados portadores da infecção, como o tatu ${ }^{(4)}$. No Brasil é mais prevalente nas regiões sul, sudeste e centro-oeste ${ }^{(5)}$. O grande fator de risco para a aquisição da infecção são as profissões ou atividades relacionadas ao manejo do solo contaminado com o fungo como, por exemplo, atividades agrícolas, terraplenagem, preparo de solo, práticas de jardinagens, transporte de produtos vegetais, entre outros. Tabagismo e alcoolismo estão frequentemente associados à Pbmicose. Ao contrário de outras micoses esta não é usualmente relacionada a doenças imunodepressoras, porém há casos associados com infecção pelo HIV, neoplasias e mais raramente transplante de órgãos.

A infecção é mais comumente adquirida nas duas primeiras décadas de vida, com um pico de incidência entre 10 e 20 anos de idade. A apresentação de manifestações clínicas ou a evolução para a doença sistêmica é incomum neste grupo, ocorrendo mais frequentemente em adultos entre 30 e 50 anos, como reativação de foco endógeno latente. A razão de acometimento da Pbmicose em adultos varia entre 10 a 15 homens para uma mulher ${ }^{(4)}$. Kamegasawa et al. resumiu $50 \mathrm{ca-}$ sos de Pbmicose ocular relatados na literatura brasileira e estrangeira. A proporção de acometimento entre sexo masculino e feminino foi de 31 para 3 , sendo $73,9 \%$ com ocupação rural, $69,6 \%$ da raça branca atingindo principalmente a faixa etária compreendida entre a década de 30 e $60^{(6)}$. Atenta-se para este caso a manifestação da doença ocular em idade mais avançada.

$\mathrm{Na}$ forma crônica as manifestações pulmonares estão presentes em $90 \%$ dos pacientes. É chamada apresentação unifocal quando a micose está restrita a somente um órgão. O pulmão pode ser o único órgão afetado em até $25 \%$ dos casos. Geralmente a doença envolve mais de um órgão simultaneamente (apresentação multifocal), sendo pulmões, mucosas e pele os locais mais acometidos pela infecção ${ }^{(4)}$. Acredita-se que o reservatório e a fonte de contaminação sejam a madeira, o solo e a poeira, que abrigariam os esporos do fungo. Para as vias de penetração, têm sido propostas a tegumentar, digestiva, a amigdaliana, mas a via inalatória vem sendo a mais aceita e comprovada, inclusive por estudos experimentais. Na maioria dos casos, a lesão ocular por Pbmicose é secundária e, em trabalhos experimentais, é referida a dificuldade de inoculação ocular do fungo ${ }^{(7)}$.

Nota-se, neste caso, como primeira manifestação clínica, lesão periocular após história de trauma com madeira, depósito comum deste fungo. Interroga-se possível Pbmicose primária ocular por contiguidade com posterior disseminação para o pulmão.

Conti-Diaz et al. realizou um experimento onde inoculava cultivos jovens em forma leveduriforme de Pbmicose por via intracardíaca em 15 cobaias. Em 13 deles foi demonstrado lesão ocular após biopsia sugerindo acometimento ocular por via hematogênica. Bertaccini et al. tentou produzir, sem êxito, lesões em olhos de quatro cobaias depositando pus rico em parasitas sobre a córnea previamente desepitelizada ${ }^{(8)}$. Silva 


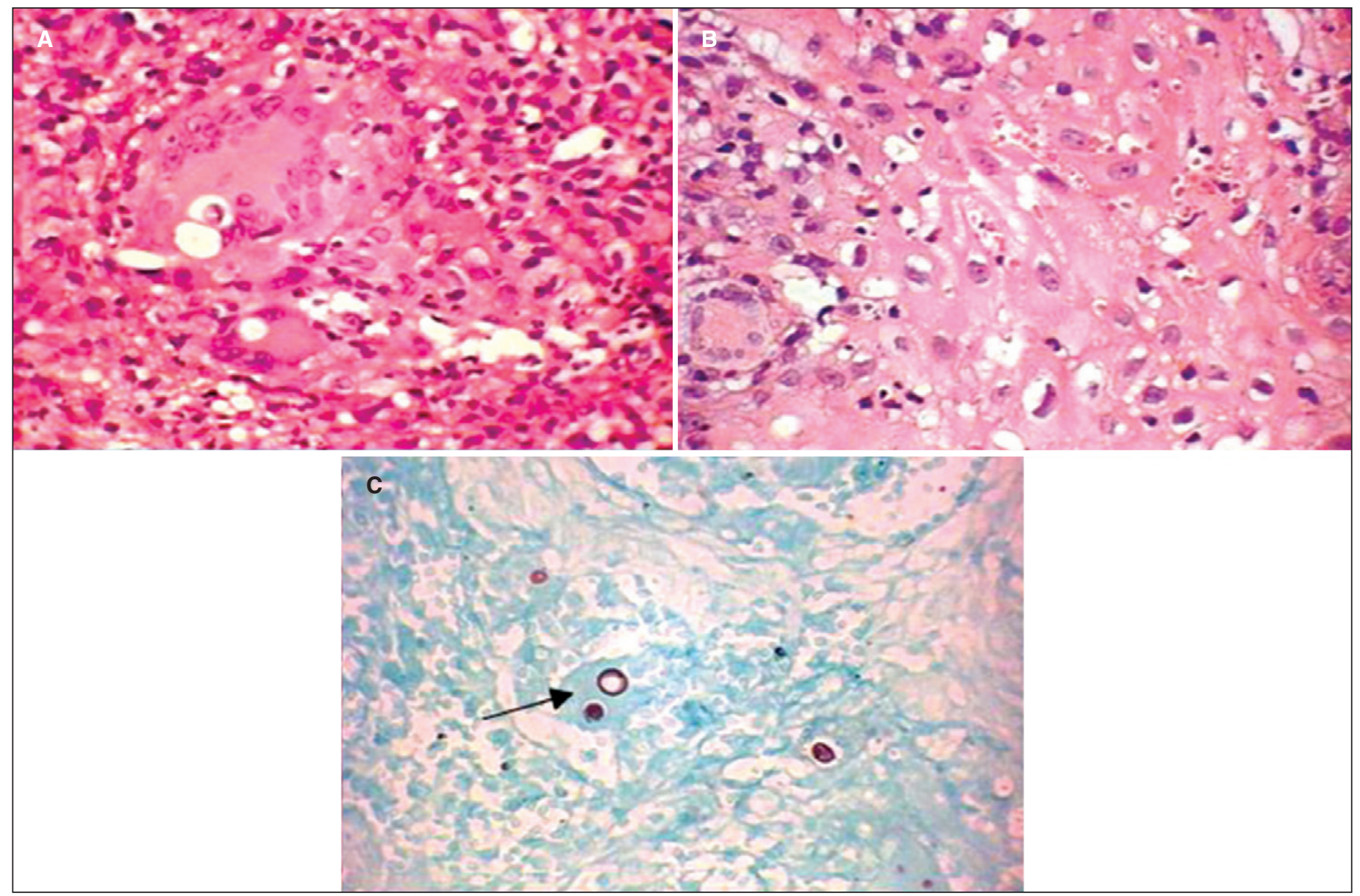

Figura 2 - Paracoccidiodomicose, processo inflamatório granulomatoso. A e B) Coloração hematoxilina e eosina; C) Coloração Grocott.

et al. relata um caso semelhante em que o paciente desenvolve Pbmicose multifocal com envolvimento ocular e pulmonar após história de trauma com galho de madeira. Coloca como duas hipóteses para a possível porta de entrada: 1) o fungo foi inalado e, após disseminação hematogênica, instalou-se na conjuntiva ocular por causa da lesão traumática; 2) o fungo foi diretamente inoculado na pálpebra com posterior disseminação para o pulmão ${ }^{(9)}$. Albornoz et al. cita caso de Pbmicose ocular que sugere entrada por inoculação direta, já que a lesão limitada ao olho se desenvolveu após trauma com material contamina$\mathrm{do}^{(10)}$. Rocha et al. relata um caso inicialmente diagnosticado como carcinoma basocelular em carpinteiro com história de lesão ulcerativa após ferimento ocular com posterior diagnóstico de Pbmicose crônica multifocal ${ }^{(5)}$. Janke et al. destaca um caso de blastomicose sul-americana tendo como primeira manifestação clínica extensa ulceração palpebral ${ }^{(7)}$.

Conclui-se que, apesar de existirem poucas evidências a partir de estudos experimentais comprovando infecção por contiguidade, não se pode descartar tal possibilidade.

A forma de apresentação da lesão ocular neste caso não fugiu a descrita pela literatura. Nas pálpebras encontram-se lesões granulomatosas com hemorragias puntiformes na base podendo envolver e até destruir ductos lacrimais. A área perilesional é edemaciada, infiltrada e hiperemiada. Na conjuntiva ocorre hiperemia difusa com secreção mucopurulenta por causa da infecção bacteriana secundária. Destaca-se a importância da inclusão da paracoccidioidomicose no diagnóstico diferencial de lesões tumorais acometendo pálpebras principalmente quando forem ulceradas ${ }^{(5)}$.

\section{ABSTRACT}

Ocular involvement of paracoccidioidomycosis is rare and when it occurs it is usually secondary to hematogenic dissemination. A case of multifocal paracoccidioidomycosis in a 73 year-old male after history of blunt trauma in the right eye with a stick of wood that presented as the first clinical sign a lidconjunctival lesion is described. The possible primary ocular infection spreading by contiguity is argued and the disease manifestation in an advanced age is highlighted.

Keywords: Paracoccidioidomycosis/diagnosis; Palpebral diseases; Diagnosis, differential; Eyelids/pathology; Conjunctiva; Case reports 


\section{REFERÊNCIAS}

1. Ferraz E, Cella W, Rocha E, Caldato R. Paracoccidioidomicose primária de pálpebra e conjuntiva. Arq Bras Oftalmol. 2001;64(3):259-61.

2. Noronha RMJ, Perez NT, Fortes HM, Hueb M, Fontes CJF. Paracoccidioidomicose ocular: relato de um caso de doença multifocal com envolvimento da pálpebra e, presumivelmente, da córnea, vítreo e retina. Arq Bras Oftalmol. 1998; 61(5):590-2.

3. Alves Pinheiro SRA, Oréfice F, Marques Mason E. Blastomicose Sul-Americana: descrição de um caso com lesões cutâneas, nasais e envolvimento do trato uveal posterior. Arq Bras Oftamol. 1987;50(2):66-9.

4. Shikanai-Yasuda MA, Telles Filho FQ, Mendes RP, Colombo AL, Moretti ML. Consenso em paracoccidioidomicose. Rev Soc Bras Med Trop. 2006;39(3):297-310
5. Rocha GJNM, Nossa LMB, Pinto MR, Marback RL. Paracoccidioidomicose palpebral: relato de três casos. Arq Bras Oftalmol. 2002;65(5):575-8

6. Kamegasawa A, Silva MRBM, Franco M, Heimbeck FJ. Paracoccidioidomicose ocular: revisão. Arq Bras Oftalmol. 1988;51(4):183-5.

7. Janke HA, Lopez FS, Abrahão MC, Thofern P, Duarte AL, Holthausen ET Blastomicose sul-americana palpebral. Rev Bras Oftalmol. 1983;42(2):157-60.

8. Conti-Diaz IA. Lesiones oculares em la blastomicosis sudamericana. Hospital (Rio J). 1960;58:903-14.

9. Silva MR, Mendes RP, Lastória JC, Barraviera B, Marques SA, Kamegasawa A. Paracoccidioidomycosis: study of six cases with ocular involvement. Mycopathologia. 1988;102(2):87-96.

10. Albornoz MB. Paracoccidioidiomycosis. First Pan American Symposium. Proceedings. Medellin/Colombia. Pan American Health Organization, 1971. p.142. (PAHO Scientific Publ. $\mathrm{n}^{\circ}$ 254). 